\title{
PATTERN OF OCCURRENCE OF OCULAR INJURIES AND THEIR FORENSIC ASPECTS
}

\author{
Timsinha $S^{1^{*}}$, Kar $S M^{2}$, Ranjeetkar $M^{3}$
}

\section{Affiliation}

1. Assistant Professor, Department of Forensic medicine, Manipal College of Medical Sciences, Pokhara, Nepal.

2. Professor, Department of Forensic medicine, Manipal College of Medical Sciences, Pokhara, Nepal.

3. Lecturer, Department of Forensic medicine, Kathmandu Medical College, Sinamangal, Kathmandu, Nepal.

\section{ARTICLE INFO}

Article History

Received : 01 March, 2019

Accepted : 26July, 2019

Published : 31August, 2019

(C) Authors retain copyright and grant the journal right of first publication with the work simultaneously licensed under Creative Commons Attribution License CC - BY 4.0 that allows others to share the work with an acknowledgment of the work's authorship and initial publication in this journal.

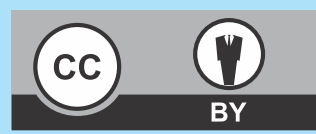

\section{ORA 115}

DOI: http://dx.doi.org/10.3126/bjhs.v4i2.25437

\section{* Corresponding Author}

Dr. Sidarth Timsinha

Assistant Professor

Department of Forensic Medicine

Manipal College of Medical Sciences, Pokhara, Nepal.

Email ID: drsidarthforensicmedicine@gmail.com

ORCID ID : https://orcid.org/0000-0003-3707-3855

\section{Citation}

Timsinha S, Kar SM, Ranjeetkar M. Pattern of Occurrence of Ocular Injuries and their Forensic Aspects. BJHS 2019;4(2)9: 692 - 696.

\section{ABSTRACT}

\section{Introduction}

All penetrating or non-penetrating intentional ocular trauma causing loss of an organ or part of an organ and which have as a consequence the facial disfigurement or post trauma sequelae formation have forensic implications.

\section{Objectives}

To study the pattern of ocular injuries its forensic implications and meticulous documentation in ocular medico-legal cases.

\section{Methodology}

This hospital based cross sectional study was carried out by Forensic medicine personnel in Department of Ophthalmology and Emergency Department of Manipal Teaching Hospital Pokhara, Nepal. A total of 251 cases of ocular injury constituted the sample size. Cases were analyzed according to age, sex, type of trauma, causative agent, and manner of injury and ocular injuries having any medico-legal value. All data was evaluated and relevant information were extracted and entered into a database.

\section{Results}

Male subjects 174 (69.32\%) were more susceptible to ocular injuries and age group 21-30 years 66 (26.30\%) were more predisposed to ocular injuries. The commonest cause of ocular trauma was due to fall on blunt objects $42(16.73 \%)$. The most common site of injury was cornea $120(47.81 \%)$ and corneal abrasion 65 (54.16\%) was the most common ocular finding. Accidental manner of injury was observed in majority of the cases 230 (91.60\%). Ocular injuries sustained were all simple in nature $251(100 \%)$ as a result no fatality was observed following ocular injury.

\section{Conclusion}

Proper history taking and methodical documentation of injuries not only assist in diagnosis and management of the patient but also holds an evidentiary value in medico-legal cases.

\section{KEYWORDS}

forensic medicine, medico legal, ocular injuries, visual acuity 


\section{INTRODUCTION}

Ocular trauma has been a neglected disorder. ${ }^{1}$ Approximately 1.6 million people globally are blind from eye injuries and 2.3 million are visually impaired bilaterally and 19 million have unilateral visual loss. Today, ocular injury is one of the most common cause of unilateral blindness in the world. ${ }^{2,3}$ The national population based survey of blindness in Nepal (1981) found a blindness prevalence rate of $0.84 \%$, with ocular trauma responsible for $7.9 \%$ of monocular blindness. ${ }^{4}$ According to a survey conducted in Nepal in 2011 the prevalence of blindness in the total population of Nepal declined significantly from $0.84 \%$ in 1981 to $0.35 \%$ in 2011 , a reduction of $58.6 \%$. The number of affected person (all ages) reduced with $20.6 \%$ from 117.600 to $93,400 .^{5}$

Ocular injuries hold forensic significance when it occurs due to trauma to the body hampering the loss of eye ball and visual acuity. ${ }^{6}$ The consequences have many facets including legal, social, and economic. ${ }^{7}$ According to Nepal - Criminal (Code) Act, 2074 chapter 14 article 192 [2] (क/A)defines grievous hurt as all injuries that causes loss of vision or loss of structure resulting in loss of vision and (ज/H)defines grievous hurt as any injury that causes loss of employability. Therefore the maltreater is penalized based on the degree of severity of those injuries. ${ }^{8}$ In practice, a legal opinion of ophthalmologist is essential as a treating ophthalmologist or expert or when the legal proceeding is against the favor of ophthalmologist during medical disputes. ${ }^{9}$ Despite, initial presentation as medico-legal case, only a small fraction of these cases are trailed in the court for which an attending ophthalmologist is called as expert witness..$^{10}$ Ideally all cases of ocular injury should be referred to a specialist for high quality advice after initial first-aid treatment. Even the remotest suspicion of an intraocular foreign body demands radiological assessment. In cases where these safeguards are not carried out actions for negligence may arise. ${ }^{9}$ In case of visual disability' the Snellen's chart forms a basis to assess loss of vision and loss of earning capacity." Such exercise is necessary in civil matters where the patient claims compensation under Motor Vehicle Accident and the Workmen's Compensation Act. ${ }^{6}$ Hence, the ophthalmologist must provide evidence of detailed eye examination, correct description of wounds and appropriate investigations to support the diagnosis. ${ }^{11}$ The quality of such evidence is defined by scientific methodology employed in the investigation. If a medical practitioner completes all those processes like writing 'wound certificate' make a 'written consent' with the patient for examination and treatment, and 'if the matter is intimated to police', his medico-legal duties can be considered up to standard. If he fails to perform these duties, a negligence suit may be filed against him in the court of law. Although, rare one must be aware of false claims put up by a malingering patient as monetary compensation or legal benefits may take place. ${ }^{9}$ The eye being the bilateral organs of visual system; its involvement by injury has medico-legal implications, both of civil and criminal nature. So, every doctor must be familiar with the procedure of examination and recording of data for medicolegal purpose. ${ }^{11}$ No such study from this region of Nepal, assessing the pattern of ocular trauma and highlighting the significance of documentation in ocular medico-legal cases has ever been reported till date.

\section{METHODOLOGY}

This is a prospective hospital-based study undertaken over a one-year period from $1^{\text {st }}$ January 2018 to $31^{\text {st }}$ December 2018 on "Pattern of occurrence of ocular injury and its forensic aspects." The sample size obtained by the convenience sampling technique was a complete case of 251. The research was performed in the Department of Ophthalmology and Emergency Department of Manipal Teaching Hospital, Pokhara by Forensic medicine personnel after receiving an ethical clearance certificate from the institution's ethical committee. Before eye examination, consent was acquired from all patients. This research included all patients attending the casualty, the outpatient department and those admitted to the hospital with history of eye trauma. Information about demographic characteristics viz. age group, gender distribution and residential status of subjects were recorded. Detailed history of injury was taken to know the time of injury, place, object of injury, its nature, manner of infliction, length of hospital stay and ocular injury of any medical-legal significance. Mechanism of injury was categorized as mechanical, chemical or thermal. Mechanical injury was further classified according to 'Ocular Trauma Classification Group' by Kuhn and Associates into closed globe and open globe injury.

A full-thickness wound of the eye wall (sclera and cornea) is defined as "open globe injury (OGI)". "Closed globe injury $(O G I)$ " is defined as one in which no full thickness wound of the eyewall is present ${ }^{12} \mathrm{All}$ the subjects of ocular trauma were examined by the ophthalmologist and the findings were then recorded by forensic personnel in a specially designed proforma. The ocular examination included visual acuity, anterior segment examination; slit lamp biomicroscopy, IOP (intraocular pressure) measurement by applanation tonometer, gonioscopy and direct and indirect ophthalmoscopy in all patients. USG (B) was carried out to assess posterior segment status particularly retinal detachment, vitreous haemorrhage and to rule out retained intraocular foreign body in patients with hazy media. Other relevant investigations like X-ray orbit/skull, CT scan and MRI were done whenever indicated. The research included subjects free of ocular disease and those reporting within 12 months period from commencement of research. The subjects with ocular disease or with age-related vision alterations as well as follow-up cases were not included in the study. All records were analyzed and relevant data was extracted and entered into a database. 


\section{RESULTS}

In this study ocular injuries in registered medico-legal cases like Road Traffic Accident (RTA), fall injuries, and physical assault constituted $42(16.73 \%)$ of total cases whereas in non medico-legal registered cases ocular injuries comprised of $209(83.26 \%)$ cases. On the whole unilateral and bilateral ocular trauma cases constituted 274 in number. Male subjects 174 (69.32\%) were more susceptible to ocular injuries than females $77(30.67 \%)$. The age group 21-30 years 66 (26.30\%) were more predisposed to ocular injuries with least incidence in extremes of ages $<1$ year $2(0.80 \%)$ and $>80$ year $4(1.60 \%)$. Table 1 depicts the gender and age distribution of ocular injuries.The majority of ocular injuries were registered as OPD cases 196 (78.10\%) while $55(21.90 \%)$ cases were registered in the casualty. The commonest cause of ocular trauma was due to fall on blunt objects $42(16.73 \%)$.The most common site of injury was cornea 120(47.81\%) with corneal abrasion 65 (54.16\%) being the most common ocular finding. Table 2,3 Majority of the patients $165(60.21 \%)$ had normal visual acuity of 6/6 in the affected eye at presentation. The least visual acuity of $3 / 60$ was recorded in $1(0.36 \%)$ case.Visual acuity was not recordable (NR) in 12 (4.37\%) patients of ocular trauma. Table no. $4 \mathrm{In}$ this study all cases of ocular trauma $251(100.00 \%)$ was simple in nature involving only the eye lids and outer ocular surface (closed globe)of the eye. Accidental manner of ocular injury were observed in majority 230 (91.63\%) of cases while homicidal manner were observed in $21(8.40 \%)$ cases with no suicidal case. Almost all cases 249 (99.20\%) of ocular injury were cured and discharged. Maximum cases $21(75.00 \%)$ had hospital stay of $1-5$ days. Only 1 (0.36\%) case was referred to a higher center for further management and another $1(0.40 \%)$ case left against medical advice (LAMA). In this study no fatality was observed following ocular injury.

\begin{tabular}{|c|c|c|c|}
\hline \multirow{2}{*}{$\begin{array}{c}\text { Age group } \\
\text { (years) }\end{array}$} & \multicolumn{2}{|c|}{ Gender } & \multirow[b]{2}{*}{ Total (\%) } \\
\hline & Male (\%) & Female (\%) & \\
\hline$<1$ & $2(0.79)$ & $0(0.00)$ & $2(0.80)$ \\
\hline $0-10$ & $22(8.76)$ & $9(3.58)$ & $31(12.40)$ \\
\hline $11-20$ & $22(8.76)$ & $11(4.38)$ & $33(13.10)$ \\
\hline $21-30$ & $51(20.31)$ & $15(5.97)$ & $66(26.30)$ \\
\hline $31-40$ & $26(10.35)$ & $11(4.38)$ & $37(14.70)$ \\
\hline $41-50$ & $22(8.76)$ & $13(5.17)$ & $35(13.90)$ \\
\hline $51-60$ & $15(5.97)$ & $10(3.98)$ & $25(10.00)$ \\
\hline $61-70$ & $8(3.18)$ & $4(1.59)$ & $12(4.80)$ \\
\hline $71-80$ & $3(1.19)$ & $3(1.19)$ & $6(2.40)$ \\
\hline$>80$ & $3(1.19)$ & $1(0.39)$ & $4(1.60)$ \\
\hline Total & $174(69.32)$ & $77(30.67)$ & $251(100.00)$ \\
\hline
\end{tabular}

Table no. 2: Distribution of causative agents of ocular injuries

$\begin{array}{lcc}\text { Agents } & \text { No } & \text { Percentage } \\ \text { RTA } & 21 & 8.36 \\ \text { Fall injury } & 42 & 16.73 \\ \text { Fist/Finger/Hand } & 21 & 8.36 \\ \text { Stone } & 9 & 3.58 \\ \text { Glass particle } & 7 & 2.78 \\ \text { Caterpillar hair insertion } & 26 & 10.35 \\ \text { Nails } & 9 & 3.58 \\ \text { Pen/pencil } & 8 & 3.18 \\ \text { Wood particle } & 24 & 9.56 \\ \text { Metal particle } & 13 & 5.17 \\ \text { Dust particle } & 12 & 4.78 \\ \text { Stone particle } & 22 & 8.76 \\ \text { Burns( Chemicals /Thermal) } & 9 & 3.58 \\ \text { Others } & 28 & 11.15 \\ \text { Total } & 251 & 100.00\end{array}$

Table No.3: Pattern of ocular injuries in relation to anatomical site

Anatomical site

No

Percentage

Eyelid

34

13.54

Laceration

18

52.94

Edema \&ecchymosis

16

47.05

Conjunctiva

80

31.87

Subconjunctival

50

Laceration

40

10

Foreign body

30

Hyperemia

24

10

Laceration

2.5

Cornea

47.81

Foreign body

40.83

Abrasion

54.16

Ulcer

4.16

Laceration

Uvea

0.83

Uveitis

3.58

Iris prolapse

66.66

Lens

33.33

Dislocation

1.59

100

Vitreous

Hemorrhage

0.79

Chemical

100

Thermal

3.18

8

0.39

Single patient might have had multiple findings (multiple responses) 
Table no. 4: Profile of visual acuity of affected eyes after sustaining ocular injury

$\begin{array}{cccc}\text { S.N. } & \text { Visual Acuity } & \begin{array}{c}\text { No. of eyes } \\ \text { affected }\end{array} & \begin{array}{c}\text { Percentage } \\ 1\end{array} \\ 6 / 6 & 165 & 60.21 \\ 2 & 6 / 9 & 41 & 14.96 \\ 3 & 6 / 12 & 22 & 8.02 \\ 4 & 6 / 18 & 15 & 5.47 \\ 5 & 6 / 24 & 9 & 3.28 \\ 6 & 6 / 36 & 6 & 2.18 \\ 7 & 6 / 60 & 0 & 0.00 \\ 8 & 5 / 60 & 0 & 0.00 \\ 9 & 4 / 60 & 3 & 1.09 \\ 10 & 3 / 60 & 1 & 0.36 \\ 11 & \text { NR } & 12 & 4.37 \\ & \text { Total } & 274 & 100.00\end{array}$

NR: Not Recordable

\section{DISCUSSION}

Medico-legal ophthalmic examination of living or dead is a major component of Forensic ophthalmology in resolving legal problem or issues. ${ }^{13}$ The medico-legal report forms the basis for the documentary medical evidence in court of law and demands detailed professional examination along with strong documentation. The report should be prepared immediately after the examination is complete. If the report stands out to be more than one page, each page should hold the signature of the doctor at the bottom of the page. The report should bear the date, time, and place of examination; the details of the patient and accompanying person. It is vital that the report should be clear, understandable and concise and complete. ${ }^{7}$ The report should avoid technical terms as far as possible and should show the competence of the doctor and lack of bias. If a definitive opinion cannot be given immediately, relevant tests should be ordered, and the patient should be kept under observation. Adult ocular injuries are usually the result of intentional assault. Males are more often affected than females and suffer injury at younger age, in contrast to pediatric ocular injuries which are usually accidental in manner. ${ }^{14}$

In our study males (69.32\%) were more vulnerable to ocular injuries than females (30.67\%). This may be due to the difference in exposure risk between males and females. This again can be attributed to the increased outdoor, occupational and sports, risky adventure seeking behavior and recreational activities with higher risk of injuries in men. Other studies also showed higher incidence of eye injuries in males than in females. ${ }^{15-18}$ Incidences of ocular injury in our study were more predominant in age group 21-30 years (26.30\%) which was consistent with other studies. ${ }^{17,18,19}$ This comprises the economically productive age group and ocular injury in this age group results in great economic loss. Increased incidence of ocular injuries among young can be explained by their frequent social activity. In our study the main cause of ocular injuries were due to fall injury on blunt objects (16.7\%). There is disparity in this finding and that of other studies. Karki DB observed non-specific agents (41.9\%) as most common cause of ocular injuries followed by metallic agents (25.3\%). ${ }^{15}$ Wooden objects (19.6\%) followed by fist injury (13.4\%) was the commonest source of ocular injury observed by Sthapit PR et al. ${ }^{18}$ According to Dulal $S$ et al dust and sand particles, leaves and thorns accounting (30.7\%) was the major objects of ocular injury. ${ }^{20}$ It is difficult to comment on the discrepancy of these causative agents as the source of injury varies pertaining to the place of incident, aggression, house hold and occupational activities, traffic accidents etc. In our study, the most common ocular injury documented was corneal abrasion $(54.16 \%)$ with cornea $(47.81 \%)$ being the most affected anatomical site. Our finding is consistent with results of Upadhyaya M et al in Bhaktapur and Oum BS et al in South Korea, where corneal abrasion has been observed to be the most common finding. ${ }^{21,22}$ Loss of eye sight or blindness during altercation is considered a crime of grievous nature and is liable to fine and /or punishment according to Nepal Criminal (Code) Act, 2074(2017). ${ }^{8}$ Here, it may be imperative to note that the treating doctor should give opinion after complete healing which may take 6 week's or 6 months or more on an average, to judge the disability or disfigurement is permanent or not as anatomical healing usually never correlate with physiological healing (i.e. vision). The visual acuity (VA), intraocular pressure (IOP) and sketch of the wounds are very important features to be documented. 'In most of the subjects $(60.00 \%)$ visual acuity recorded was $6 / 6$. Visual acuity was not recordable in $(4.40 \%)$ cases as this proportion constituted pediatric age group of $<4$ years. Our finding is in accordance to a study conducted by Voon LW et al wherein $(82.70 \%)$ cases, visual acuity was 6/6 - 6/9. ${ }^{23}$ Similarly, Sthapit PR et al noticed visual acuity was better than 6/12 in (83.92\%) patients of ocular injury. Additionally he mentioned visual acuity could not be assessed in three cases of pediatric age group. ${ }^{18}$ The better visual acuity in the above studies and ours is due to the fact that maximum cases consisted of simple ocular trauma in the form of foreign body insertion, lid abrasion, lid laceration, lid oedema and ecchymosis without having significant effect in the visual acuity. However, in contrary Titiyal GS et al found patients $(30.90 \%)$ were blind at presentation with visual acuity of $<3 / 60$.This is because the ocular injury sustained by the victims were that of open globe injury which significantly affected the visual acuity. ${ }^{24}$ Any ocular injury can be classified under three groups namely 1 . Simple 2.Grievous and 3.Eye injuries dangerous to life for all medico-legal purposes. The basic manner of mechanical injuries are accidental, suicidal or homicidal, which are 
associated with legal problems and may end up in consumer court or criminal court. ${ }^{13}$ All the study subjects in our study had sustained simple ocular trauma involving the lid and outer ocular surface without any significant injury affecting the globe. The majority of ocular injuries were accidental (91.60\%) in manner which occurred due to fall on blunt objects. Homicidal case was observed to be $(8.40 \%)$ that resulted out of physical assault. Almost all patients (99.20\%) in our study setting were cured and discharged with a mean duration of hospital stay of 4 days. In this study no fatality was observed following ocular injury. There was no case of medical negligence and also, no patient was detected to feigned ocular trauma to register themselves as medicolegal cases.

\section{CONCLUSION}

Ophthalmologists are an integral cog of the medico-legal system for justice delivery. Proper history taking and documentation not only assists in diagnosis and management of the patient but also holds an evidentiary value in medico-legal cases. It is therefore important for every doctor to be familiar with procedures of ocular examinations as well as good record keeping to ensure that there is no medico-legal liability on his/her part.

\section{REFERENCES}

1. Parver L. Eye trauma. The neglected disorder. Arch Ophthalmol 1986;104(10):1452-3. PMID: 3767673

2. Chua D, Wong WL, Lamoureux EL, Aung T, Saw SM, and Tien $Y$. The Prevalence and Risk Factors of Ocular Trauma: The Singapore Indian Eye Study. Ophthalmic Epidemiology. 2011;18 (4):164-70. PMID:22053838

3. Soylu M, Sizmaz S, Cayli S. Eye injury (ocular trauma) in southern Turkey: epidemiology, ocular survival, and visual outcome. Int Ophthalmol. 2010;30(2):143-8. PMID:19190858

4. Khatry SK, Lewis AE, Schein OD, Thapa MD, Pradhan EK, Katz J. The epidemiology of ocular trauma in rural Nepal. $\mathrm{Br} J$ Ophthalmol 2003;88(4): 456-60. PMCID:1772092

5. Sapkota YD. The Epidemiology of Blindness in Nepal: 2012. Kathmandu: Nepal Netra JyotiSangh; 2012.

6. Parmar SPS and Desai SS. Law of Disability (Medical and Non Medical). Dwivedi and Co.,Allahabad,India,2004.

7. Tripathy K, Chawla R, Venkatesh P, Vohra R, Sharma YR. Clinical profile of medicolegal cases presenting to the eye casualty in a tertiary care center in India. Indian J Ophthalmol 2016; 64:422-6.

8. Nepal - Criminal (Code) Act, 2074 (2017). 75 p. Available from: http://www.lawcommission.gov.np

9. Shaw, M. (1976). I Eye Injuries: Medicolegal Aspects. Proceedings of the Royal Society of Medicine, 69(1), 65-66. https:// doi.org/ $10.1177 / 003591577606900134$.

10. Raju KV. Medico Legal Aspects of Ocular Injury. Kerala Journal of Ophthalmology 2010;22(3):277-8.

11. Costea CF, Sava A, Dumitrescu GF, Albert M, Cucu A, Turliuc A et al. Forensic Aspects of Ocular Trauma. Aperito J Ophthalmol 2015;1:109-13. DOI:10.14437/AJO-1-109

12. Kuhn F, Morris R, Witherspoon CD, Heimann K, Jeffers JB, Treister G. A standardized classification of ocular trauma. Ophthalmology 1996;103:204-3. PMID:8594508

\section{RECOMMENDATION}

We recommend detailed documentation and investigations of patients with ocular injuries, so that forensic evidence should be adequate, correct and comprehensive for the correct classification of the offense and delivery of justice according to the Penal Code of the country.

\section{LIMITATIONS OF THE STUDY}

This study was conducted in single tertiary care hospital. Different hospitals are to be surveyed involving more subjects to recognize and study medico-legal ocular injuries in depth.

\section{ACKNOWLEDGEMENT}

We are thankful to all the staffs of department of Ophthalmology, department of Emergency and department of Forensic medicine of Manipal Teaching Hospital, Pokhara, Nepal for their help and support.

\section{CONFLICT OF INTEREST}

Authors declare that there is no conflict of interest.

\section{FINANCIAL DISCLOSURE}

None

13. Pillay V V .Comprehensive Medical Toxicology. Hyderabad: India; Paras Medical Publisher; 2003.p.8-10.

14. Lyon IB, Dogra TD, Rudra A. Lyon's Medical Jurisprudence and Toxicology. 11th ed. Delhi: India Delhi Law House; 2005.p.367.

15. Karki DB. Ocular Morbidity due to Injury. PMJN 2008;8(1):1-9

16. Nadeem S, Ayub M, Fawad H. Visual Outcome of Ocular Trauma. Pak J Ophthalmol 2013;29(1):34-39.

17. Mallika PS, Tan AK, Asok T, Faisal HA, Aziz S, Intan G. Pattern of ocular trauma in Kuching, Malaysia. Malays Fam Phys 2008;3(3):140-5. PMID: 25606139

18. Sthapit PR, Marasani S, Khoju U, Thapa G, Nepal BP. Ocular trauma in patient presenting to Dhulikhel Hospital. Kathmandu Univ Med J 2011;9(33):54-7. PMID:22610811

19. Qureshi MB. Ocular injury Pattern in Turbat, Baluchistan, and Pakistan. Com Eye Health Journal 1997:10(24):57-8.

20. Dulal S, Ale JB, Sapkota YD. Profile of pediatric ocular trauma in midwestern hilly region of Nepal. Nepal J Ophthalmol 2012;4(7):1347.PMID: 22344011

21. M Upadhyay, P Karmacharya, S Koirala, D Shah, S Shakya, J Shrestha, H Bajracharya, C Gurung and J Whitcher. Bhaktapur eye study: ocular trauma and antibiotic prophylaxis for the prevention of corneal ulceration in Nepal. Br J Ophthalmol 2001;85:388-92. PMID: 11264124

22. Oum BS, Lee JS, Han YS. Clinical Features of Ocular Trauma in Emergency Department. Korean J Ophthalmol 2004;18:70-78. PMID:15255241

23. Voon LW, See J, Wong TY. The epidemiology of ocular trauma in Singapore: perspective from the emergency service of a large tertiary hospital. Royal College of Ophthalmologists 2001;15:75-81. PMID: 11318302

24. Titiyal GS, Prakash C, Gupta S. Pattern of ocular trauma in tertiary care hospital of Kumaon Region, Uttarakhand. J Indian Acad Forensic Med 2013;35(2):116-9. 